\title{
Assessment of Benefits and Disadvantages of Implementing Cloud-Specific Solutions in Polish Companies on the Example of ERP Systems
}

Remigiusz Zieliński ( $\nabla$ remigiusz.zielinski@pcz.pl )

Politechnika Czestochowska https://orcid.org/0000-0002-8575-456X

Sebastian Kot

Politechnika Czestochowska

Katarzyna Zielińska

Akademia Wychowania Fizycznego imienia Jerzego Kukuczki w Katowicach

\section{Research}

Keywords: cloud computing, ERP, business support, enterprise

Posted Date: June 18th, 2020

DOI: https://doi.org/10.21203/rs.3.rs-34147/v1

License: (1) This work is licensed under a Creative Commons Attribution 4.0 International License.

Read Full License 


\section{Abstract}

Both dynamics and environmental turbulences result in constant updating of IT and communication specific technologies utilized within the scope of various organizations. The Polish IT market is characterized by a dynamic development of the cloud data processing model that offers access to various resources via the network in the form of convenient services. The transfer of IT systems (including ERP) to the cloud is a complex process and while the connection can be made, it may be met with a number of problems. The predominant aim of the article, aside from theoretical considerations, is to showcase the possibilities of supporting a company's operational schemes by means of IT solutions available within the cloud; as well as to indicate both the benefits and the difficulties Polish companies have to face while implementing cloud computing specific solutions. Within the scope of the article, selected outcomes of questionnaire surveys are going to be presented. Research results have shown that IT solutions and ERP systems available in the cloud have been positively perceived by the respondents, especially with regard to improving the overall operational efficiency of companies.

\section{Introduction}

The development and proper functioning of modern organization is to a great extent determined by the purchased and implemented IT technologies. As a result, there is a constant increase in the demand expressed by various types of organizations (both business and non-business ones) and individual users for advanced technologies that would be not only highly functional, but also financially beneficial. A relatively new service that can be taken advantage of by various companies is the so-called Cloud Computing paradigm that is predominantly oriented towards the use of services provided by an external service provider within the framework of a specific license agreement. In the case of the discussed model, clients are ensured a comprehensive technical support and the access to their data. Thanks to that, there is no need for them to install certain applications on their own computers or to make any updates. To be able to take advantage of services offered, they just have to have Internet access.

The major goal of this article is to present the possibilities of supporting the operation of companies by means of opting for IT solutions available in the Cloud, such as ERP systems for example. An auxiliary aim of this paper is to specify the current state and development perspectives of Cloud-based solutions in the analyzed group of Polish entrepreneurs, as well as to identify both advantages and disadvantages connected with the implementation of the Cloud computing model. The literature of the subject provides results of examinations on the utilization of Cloud Computing in companies, but such publications typically refer to foreign business entities rather than to those Polish ones. Due to a varying level of company digitization in Poland, the dynamic development of IT and communication-oriented technologies, and the constantly expanding offer of IT solutions available in the Cloud, it is paramount to carry out examinations focusing on the perception of the discussed solution by Polish companies and organizations. While carrying out a survey exclusively among companies utilizing some kind of services available in the Cloud Computing model, the authors have formulated the following research question: how is the Cloud perceived by Polish companies? To achieve the goal of the article specified at the 
beginning, the notion, specificity, and available Cloud Computing services are going to be specified within this paper. Afterwards, both positive and negative aspects of the Cloud and its potential with regard to supporting the operation of companies are going to be discussed. The final part of the article is going to focus on the presentation of the outcomes of a survey carried out on the sample of SME companies utilizing some Cloud-based solutions in their everyday operation.

\section{Literature Review}

Cloud computing is a completely new method of cooperation between users and IT-related service providers [1]. It is predominantly based on replacing local IT solutions with services that are being provided in a digital manner via the World Wide Web. The utilization of services offered by Cloud computing-related service providers makes it possible to forget about the necessity to deal with technical side of IT solutions, such as, among others, administration, infrastructure, and software-specific issues. It in turn allows to focus on key business processes, resulting in generating added value for the user. The utilization of Cloud-specific solutions may directly translate into boosting the overall technological advancement, especially in comparison to user's or company's proprietary solutions. What is more, costs of utilization of IT systems can be lowered to a remarkable extent thanks to said approach [2].

NIST (National Institute of Standards and Technology) has defined Cloud computing as „a model based on making a network of shared, configurable resources (such as computer networks, servers, mass storages, pieces of software and services), available to the users with the resources in question being easily adjustable. Furthermore, said resources can be provided with minimum involvement of implementation-oriented teams, including service providers" [3]. Cloud computing is a method of calculation, in the case of which dynamically scaled IT resources are made available to users on demand in the form of network services [4]. It is an approach oriented towards taking advantage of tools and services via a digital network directly [5]. Cloud computing is based on a service provider (an external organization or an internal department of a given organization) offering IT services via a particular network (local network or the Internet) that are provided by opting for the infrastructure and pieces of software made available by the provider.

Cloud computing may cover the following [6]:

- Cloud management system,

- virtual server provision system,

- portal for administrators and users,

- available service catalogue,

- monitoring system,

- service utilization settlement system.

Cloud computing solutions are typically realized in one of the following forms [7]: 
- Software as a Service (SaaS) - those are IT applications characterized by specific functionalities and parameters (e.g. financial, accounting-oriented, ERP, and CRM) made available to the users via the Internet; in the case of the discussed solution, the user manages only the applications he or she has been granted access to via the Internet (server and runtime environment are managed by the service provider);

- Communications as a Service (CaaS) - in said scenario, the service provider grants users access to a telecommunications platform (e.g. e-mail, communicators, voice communication, video communication), which can be utilized via the Internet; both the hardware layer (servers, phones, cameras, headphones) and integrated application layer are then offered and managed by the service provider.

- Platform as a Service (PaaS) - a ready-made IT platform compliant of the prior agreed specification (e.g. database, application server, programming tools) is made available by an external service provider via the Internet; the recipient is offered a comprehensive IT solution, as well as a fully functional runtime environment for applications taken advantage of within the scope of a given company or organization;

- Infrastructure as a Service (laaS) - a comprehensive IT infrastructure having the form of a specific hardware platform, for example, a virtual server characterized by highly specific parameters (CPU, RAM, hard disk drive, number of network cards) made available via the Internet by an external service provider; such a solution allows to freely manage the IT infrastructure offered by the service provider (there is the possibility of selecting and installing the preferred operating system and applications);

- Business Process as a Service (BPaaS) - service provider ensures solutions allowing for a comprehensive realization of a specific business process, without the necessity of the user to utilize own IT solutions and resources.

Cloud computing can also be classified by approaching it from the ownership-related point of view. While taking said criterion into account, the following solutions can be enumerated [8]:

- public cloud - service offered publically via the Internet to an unlimited number of possible recipients; all the users take advantage of the same infrastructure that is being provided by external companies.

- private cloud - a single user (e.g. an organization) takes the full advantage of a given IT-related solution (infrastructure, application layer, set of services); in the discussed model, the user manages his or her proprietary IT infrastructure; one may also opt for solutions where the infrastructure is managed and provided by external companies via the Internet.

- hybrid cloud - it is a combination of the abovementioned approaches, namely - private and public cloud; the user can decide which services are going to be provided by external companies (e.g. e-mail account, CRM) and which ones will be managed on his or her own (e.g. confidential data storage).

Basic features of services provided in the Cloud computing model are as follows [9]: 
- cost distribution - costs connected with managing a given hardware platform (costs of devices, power supply, cooling, maintenance) and programming platform (virtualization system, operating systems, applications) are divided between all the users of a specific service;

- flexibility and scalability - the service provider has the possibility of dynamically adjusting the offered services to the constantly changing needs of the client (processing power, disk space, network throughput); if need be, the user can request the service provider to lower or increase the efficiency of the prior selected service without making any amendments to the proprietary IT infrastructure; in said scenario, the user can easily add new useful services to the platform or opt out of using those which have proved to be inefficient or redundant;

- functionality as a service - functions provided within the scope of Cloud computing (such as processing power, mass data storage, programming environment, applications) are all offered as a service; implementation method is typically unclear to the user. The important thing is for the service to meet his or her requirements and expectations;

- pay per use settlement model - the user pays for the factual use of a given service. Thanks to that, he or she can limit the cost of managing the IT-related infrastructure (hardware + software); service cost can be calculated basing on various parameters, such as: usage time, processing power utilization, number of application launches, use of the available disk space, network bandwidth usage, etc.;

- online availability - for the services offered in the Cloud to be available, one has to have the access to the Internet; the only exception from the rule is the usage of said services by users being Cloud owners, when they are connected to it by means of a local network;

- safety - service provider ensures the full stability of offered services by opting for safe data centers, auxiliary infrastructure, constant system monitoring, power supply supervision, and malfunction detection; yet another aspect that affects the overall safety of the discussed solution is the diversification of location of processing centers (placing them in various political, geological, and climatic areas), which additionally secures IT-specific resources against the outcomes of catastrophes, disasters, or terrorist undertakings; to protect the system from hacking attempts that may cause valuable data to be accessed by unverified users or deleted, the service provider ensures constant improvement of the competences of the employed team, as well as regular updating of the offered solutions; it also has to be pointed out that a Cloud user has no certainty that data stored by him or her in the Cloud will not be taken advantage of in an inappropriate manner (e.g. data disclosure) by the Cloud management team;

- ecology, energy saving - severs utilized within the scope of a Cloud-based system are typically more efficient in terms of the utilization of the available processing power, memory, and disk space, especially in comparison to servers set up by individual users; a set of servers managing requests of a specific number of users requires less power than separate servers taking care of users' requests individually;

- self-servicing on demand (service catalogue) - users can order and receive vital resources necessary for data processing on demand (disc space, processing power, access to applications, access to 
databases, etc.);

- virtualization - it is a solution that allows for creating efficient and effective IT-related solutions in the Cloud computing model; it allows to exploit the available resources better, which in turn translates into lower IT infrastructure management costs;

- ease of implementation - use of services offered within the scope of the Cloud computing model is typically remarkably easier and quicker than setting up and managing one's own IT solutions allowing for the access to specific services (e.g. own server room managing a CRM system, mailing system, website-specific server, etc.).

The utilization of Cloud computing solutions is strictly connected with certain limitations that can be further classified as technical, legal, and mental ones [10]. Among the technical issues, the most prominent are:

- software compatibility issues - they may be identified especially in the PaaS model; if they happen to occur, the user may not be able to launch a given application by using the provided operating environment,

- Internet connection - the majority of Cloud computing-related services (except for private LAN Cloud solutions) require the access to an efficient Internet connection (low bandwidth may make it difficult or even impossible to take advantage of the offered services); then, it is advised to consider the possibility of connection with the service provider being lost (connection malfunction), as well as the impact such an event may have on the organization as such; an additional Internet connection may prove to be a sensible and reliable solution in the discussed case,

- imposing certain solutions - the utilization of a specific service is connected with the acceptance of technical and software-related solutions offered by the service provider; the user may be granted access to functions and applications that are considered by him or her to be redundant, but which cannot be cancelled or even limited.

Among the legal problems, the most prominent are [11]:

- choice of law system and jurisdiction - foreign companies offering Cloud computing-related services have to comply with legal regulations applicable in their countries of operation; the user should check whether or not there is the possibility of selecting the legal system and jurisdiction while ordering a given service,

- personal data protection - one of key factors that have to be taken into consideration while making a decision to take advantage of Cloud computing-specific services is personal data protection; due to the fact that the storage of personal data of users outside their country of residence is connected with a remarkable number of legal regulations, one should specify where personal data will be processed (within the borders of Poland, European Union, or elsewhere) not to breach applicable legal regulations. 
Other aspects making the utilization of Cloud computing difficult are those mentality-specific ones. Among them, there are [12]:

- software errors - the lack of a proper level of data isolation between various users sharing the available resources,

- limited trust in modern technologies - some users are rather reluctant to opt for new, untested solutions; it may be caused by either the lack of proper knowledge on Cloud processing or by a conscious choice (made basing on the prior carried out analysis of advantages, disadvantages, and risks of the solution in question),

- illegal data copying - as a result of improper supervision over rooms in which servers are stored or below-average disc utilization - faulty cleaning procedures and improper disposal of either operational or worn-out parts, especially disks with data saved on them,

- data safety-related anxiousness - in the case of the Cloud computing model, the user has the guarantee of a greater safety than it would be with standard models (lower risk of system malfunctioning, data backups, top quality hardware, highly skilled professionals), but he or she also loses full control over his or her IT resources (they may be accessed by unauthorized bodies),

- service provider reliability-related anxiousness - the user may be worried that the service provider may opt for disadvantageous or dishonest undertakings, such as unjustified price increasing, removal of certain services from the offer, or requesting the user to change the utilized technology; the user should avoid being excessively dependent on the solutions offered by a single provider.

While analyzing offers of ERP system providers available on the Polish market, one may notice that a gradually increasing number of them have introduced an additional model of distribution and use of the offered systems. Within the scope of ERP-specific Cloud computing, users may take advantage of services of such companies as: SAP, Oracle, Comarch, IFS, Exact Software, BPSC, Macrologic, Madar, Microsoft, Soneta, Sygnity, and Unit4 [13].

The distribution and use of ERP systems in the Cloud may take various forms. On the one hand, the offered solutions can be classified by taking into consideration IT infrastructure ownership (private, public, or hybrid cloud) and on the other hand - by opting for the division including basic models offered by Cloud computing service providers (SaaS, PaaS, laaS) [14].

One of the most commonly selected models is the SaaS (Software as a Service) one. Within the framework of the discussed model, one infrastructure of the service provider, one database system, and one application is utilized by many users at the same time. The client has the access to the system characterized by specific functionalities and capabilities and, in the majority of cases, has only limited possibilities of modifying it. The discussed solution is characterized by remarkable limitations when it comes to the adjustment of the system to the needs of the client. ERP systems offered in the SaaS model typically offer a less extensive scope of functions in comparison to its versions installed directly in the IT environment of the client. They are often considered to be a cheaper alternative to software offered in a traditional model (installation in the IT environment of the client). Within the scope of the discussed 
model, the client is granted access (after opting for one of available subscriptions) to an ERP system that is fully managed and supervised by the service provider (who may or may not be the ERP system producer). The service provider assumes the full responsibility for updating the system and ensuring its fault-free operation [15].

A different approach that is available is taking advantage of an ERP system functioning in a private cloud. In the discussed model, the ERP system is installed on a separate server (typically a virtual one) and is utilized by one client only. The aforementioned solution allows for better adjusting the system to the specificity and expectations of the client. It also makes it possible to address his or her individual needs at the stage of system implementation, as well as during regular use. The client may utilize a private cloud being a part of his or her own data center (the client is then responsible for managing the IT infrastructure) or dedicated cloud that is a part of the data center of the ERP system provider or a company cooperating with it (said approach allows the client to transfer responsibilities connected with IT infrastructure management to the service provider). The private cloud-oriented solution ensures higher security and control level [16].

Yet another potential scenario is the use of the so-called hybrid cloud. In the said case, the service provider, together with the client, agree upon ERP system's elements that are going to function in the public cloud (e.g. CRM) and in the private cloud (e.g. confidential data storage). The scale of operation of the client is of remarkable importance while selecting the most suitable ERP distribution model [17]. When it comes to small enterprises, the choice of a dedicated private cloud may turn out to be impossible due to costs such a solution may generate. For small and medium enterprises that are in need of a remarkably simple ERP software, a public cloud-based solution may turn out to be the best choice. In the case of big companies requiring a complex and comprehensive ERP system due to the specificity, scope, and scale of performed undertakings, a solution that is strictly oriented towards utilizing a dedicated private cloud may be the optimal solution. Quite frequently, aside from functionalities typical for ERP systems (such as finance, purchase, stock, production, sales, marketing, project, asset, servicing, human resource, and CRM management), service providers offer additional Cloud-based solutions (compatible with the selected ERP system) that may support the company's operation, such as:

- Business Intelligence tools and systems;

- tools allowing for data archiving and sharing, as well as for making backup copies;

- Office 365 software - by Microsoft;

- online shop management tools;

- services allowing to: integrate with social media (Facebook, Twitter, Google+), synchronize data between utilized applications, integrate with other pieces of software used (e.g. SQL, Oracle, SAP, MangoDB), manage identity, and manage access;

- supply management tools and systems [18]. 
A characteristic feature of Cloud-based ERP systems is a unique settlement model. When it comes to the SaaS approach, the user pays a prior agreed monthly subscription fee for taking advantage of the system, which is strictly connected with the lack of necessity of undertaking a substantial initial payment to purchase the system. When the client opts for a solution based on a dedicated cloud (such as the laaS model), he or she is going to pay for the available IT infrastructure (required for the ERP system to work) every month, basing on its factual exploitation (e.g. used processing power, data transfer, etc.). A different issue is to agree upon the payment for the provided ERP system - it may be one-off in character or take the form of a subscription fee [17]. While specifying fees for the Cloud-based ERP system utilization, service providers may take the following aspects into account:

- branch of industry (e.g. production, commerce, distribution, transportation, logistics, finances, accounting),

- selected modules (e.g. finances, accounting, assets, CRM, warehouse, production, servicing, etc.),

- additional services and functionalities (EDI communication, separate website for suppliers and clients, document circulation management, document scanning, OCR, high volume storage management, GPS monitoring, etc.),

- amount (of users, invoices, products, BOM production-specific databases, clients, suppliers, application launches),

- usage time, available processing power use [19].

Cloud-based ERP systems turn out to be an intriguing offer for companies which do not want or simply cannot cover costs connected with purchasing an ERP system and/or maintaining the IT infrastructure required for it to function properly. They may be interested in the selected solution to be implemented quickly, be efficient, scalable, as well as to ensure top tier data security.

\section{Methodology}

The major goal of the carried out examinations has been to specify the impact of Cloud utilization and ERP system implementation on changes in the overall companies' operational efficiency.

Detailed goals that have been formulated have been to analyze and assess the current state of Cloud utilization in companies, examine threats and benefits connected with implementing ERP systems available in the Cloud in the examined firms, as well as to check perspectives of their further development in the aforementioned business undertakings.

The source of empirical materials used for this article has been questionnaire surveys carried out from March to October 2019 by means of opting for the nonprobability sampling method [20]. Said method is a typical example of non-random sampling that is based on a completely subjective selection of the examined respondents. The sample consisted of 290 questionnaires. Examinations were carried out for all kinds of small and medium enterprises, as well as for micro-enterprises and large companies operating within the borders of Poland. The analysis of the responses has shown that the distribution of 
companies with regard to their size was rather proportional: the survey included $31 \%$ large-scale companies, $27 \%$ medium enterprises, $25 \%$ small firms, and $17 \%$ micro-enterprises. The latter group was the smallest one with regard to the number of companies analyzed (Table 1).

Table 1

Sample structure with regard to employment size

\begin{tabular}{|lll|}
\hline Employment & Frequency & Percentage \\
\hline$<10$ & 49 & $17 \%$ \\
\hline 10 to 49 & 73 & $25 \%$ \\
\hline 50 to 249 & 78 & $27 \%$ \\
\hline$>250$ & 90 & $31 \%$ \\
\hline Total & 290 & $100,00 \%$ \\
\hline
\end{tabular}

While taking into account the fact that Cloud solutions may be implemented in each and every enterprise, regardless of the type of business undertaking and company size, it has been assumed that questionnaires were addressed to firms operating in various branches of industry. Due to the specificity of the examination, 290 questionnaires were sent to company representatives. 27 of them were not returned and 7 of them did not meet formal requirements, so the final sample included 256 properly filled in questionnaires.

Questions for the questionnaire were formulated basing on the review of the available literature on the use of Cloud Computing in companies, as well as on the accessible reports including the outcomes of research on the utilization of Cloud-specific solutions. The questionnaire presented to enterprise representatives was divided into two parts: respondent's particulars and questions relating to the use of the Cloud. Said questionnaire included questions with one answer to choose, as well as those allowing to choose one of 5 options and being based on 5-level Likert scale, which is a bipolar interval scale. The scale used within the scope of the discussed examination incorporated 5 properly ordered answer categories. The analysis of research outcomes has been based on the comparison and interpretation of scores for individual items and for individual respondents. The examination was carried out by opting for the Computer Assisted Telephone Interviewing method. Interviews were conducted via phone and the provided answers were written down in a computer script that allowed for the full automation of the questionnaire. Microsoft Excel and SPSS Statistics were used to gather and compare data collected.

The analysis of the gathered pieces of information has shown that production-oriented companies had the biggest share in the examined sample (37\% share), followed by transportation-related firms (31\%), and commerce-specific enterprises (15\%). The sample also included service provision-oriented companies (10\%), construction firms (4\%), as well as tourism and recreation-related ones (3\%) (Fig. 1). 
The questionnaire also included a question relating to the position of the respondent in the company analyzed. The survey was addressed to individuals who, basing on their position, should have had sufficient knowledge about Cloud Computing and should have been able to answer the follow-up questions. In the discussed case, almost a half of the surveyed individuals were experts of various kinds (46\%), followed by IT workers (20\%), managers (18\%), and company owners or members of the board $(16 \%)$. It may therefore be stated that the questionnaire was filled in by people who were knowledgeable in terms of the importance of IT solutions in a company, the specificity of the Cloud Computing model, as well as who could affect decisions strictly relating to the utilization of the Cloud in a particular enterprise (Fig. 2).

\section{Results And Discussions}

Yet another question asked was related to the aim of implementing Cloud-specific solutions in the company. When it comes to the aforementioned question, respondents were asked to choose 5 most relevant answers. As it has been concluded, the most important goal of implementation of Cloud Computing solutions was limiting operational costs $(86 \%)$, which can be seen in Fig. 3 . Another important goal specified by respondents and relating to Cloud Computing-specific services was improving work efficiency by allowing for easier access to IT-related solutions (73\%).

A vital goal for opting for Cloud Computing services was also to achieve better accessibility understood as an easier access to data from various locations and computer stations (65\%). It has to be noted that an improved accessibility is not only one of main ideas behind the Cloud, but also - one of foundations of its operation. It has also turned out that respondents found the improvement of customer servicing quality $(57 \%)$ and efficiency improvement $(57 \%)$ to be of importance. Aside from that, they also pointed to security boost (35\%) and improved cooperation with partners (33\%). Interestingly enough, one of key features of the Cloud Computing model, namely - flexibility and scalability, was considered to be important by $25 \%$ respondents only. The focus on the key fields of operation of the company was even less important for the surveyed individuals (17\%). The acquisition of new markets and clients was considered by a marginal number of respondents to be paramount (9\%). As it can be concluded, Cloud Computing was still not perceived as a key tool in supporting business strategies oriented towards the acquisition of new clients.

The respondents were also asked about the benefits connected with the use of the Cloud perceived through the prism of four aspects: technological, organizational, economic, and social one. 
Table 2

Benefits connected with the implementation of the Cloud-based ERP system in the technological aspect

\begin{tabular}{|llllll|}
\hline Type of benefit & $\begin{array}{l}\text { No } \\
\text { benefit }\end{array}$ & $\begin{array}{l}\text { Slight } \\
\text { benefit }\end{array}$ & $\begin{array}{l}\text { Hard to } \\
\text { tell }\end{array}$ & $\begin{array}{l}\text { Remarkable } \\
\text { benefit }\end{array}$ & $\begin{array}{l}\text { Great } \\
\text { benefit }\end{array}$ \\
\hline Higher efficiency of IT solutions & $0.00 \%$ & $18.36 \%$ & $14.84 \%$ & $30.86 \%$ & $35.94 \%$ \\
\hline $\begin{array}{l}\text { Greater accessibility (ability to use various } \\
\text { devices from various locations) }\end{array}$ & $0.00 \%$ & $22.66 \%$ & $14.06 \%$ & $34.77 \%$ & $28.52 \%$ \\
\hline $\begin{array}{l}\text { Possibility of using technologically } \\
\text { advanced IT resources (hardware, software, } \\
\text { services) }\end{array}$ & $4.30 \%$ & $9.77 \%$ & $29.69 \%$ & $43.75 \%$ & $12.50 \%$ \\
\hline $\begin{array}{l}\text { Greater security level } \\
\text { Higher flexibility and scalability }\end{array}$ & $7.03 \%$ & $18.36 \%$ & $20.70 \%$ & $33.59 \%$ & $20.31 \%$ \\
\hline $\begin{array}{l}\text { High quality of technical support ensured } \\
\text { by the provider }\end{array}$ & $5.86 \%$ & $21.48 \%$ & $22.66 \%$ & $33.59 \%$ & $16.41 \%$ \\
\hline
\end{tabular}

The most important benefit from the technological point of view (Table 2) was, in the opinion of the respondents, a higher efficiency of IT solutions (67\% of "remarkable benefit" and "great benefit" responses - said answer percentage calculation scheme is going to be utilized in the remainder of the article as well). Other important benefits specified by the surveyed individuals were greater accessibility understood as the possibility of utilizing Cloud Computing in a mobile manner by means of using various devices (63\% of all answers), possibility of using technologically advanced IT resources (56\%), and greater security level $(54 \%)$. Aspects that were selected the least were high quality of technical support ensured by the provider (46\%), as well as independence from the utilized hardware and software (45\%). It may be considered surprising that a greater quality of technical support was perceived by the respondents as rather unimportant, but it could be caused by an insufficient efficiency of some IT solution providers with regard to customer support at the time of the survey execution.

When it comes to the organizational aspect, such benefits as the ease of utilization of IT resources (65\%) and ensuring a better business continuity $(62 \%)$ were typically chosen by the surveyed individuals while being asked about the benefits of Cloud-based ERP systems. The easiness of resource use is the result of convenient sharing of data and documents stored in one place, which also translates into ensuring a more satisfactory business continuity. Other important benefits of the Cloud Computing model turned out to be transferring the responsibility for IT resource functioning and development to the provider (59\%) and more efficient IT infrastructure management (58\%). Said benefits are strictly connected with one another, because easier IT infrastructure management is the result of, among others, transferring the responsibility for IT resource functioning and development to the provider of Cloud Computing solutions. Respondents were not keen on pointing to the such benefits as lowered need for IT employees (43\% of all answers only) or the increase of the pace of company's development (38\%) as being important advantages of implementing Cloud-based ERP systems. The negligible interest in the latter benefit may signalize that at the moment of survey execution, Cloud-based IT solutions were not perceived as major 
tools allowing for company's development. Organizational benefits of implementing Cloud-oriented ERP solutions are presented in Table 3.

Table 3

Organizational benefits of implementing Cloud-oriented ERP solutions

\begin{tabular}{|c|c|c|c|c|c|}
\hline Type of benefit & $\begin{array}{l}\text { No } \\
\text { benefit }\end{array}$ & $\begin{array}{l}\text { Slight } \\
\text { benefit }\end{array}$ & $\begin{array}{l}\text { Hard to } \\
\text { tell }\end{array}$ & $\begin{array}{l}\text { Remarkable } \\
\text { benefit }\end{array}$ & $\begin{array}{l}\text { Great } \\
\text { benefit }\end{array}$ \\
\hline $\begin{array}{l}\text { Ease of utilization of IT resources (access } \\
\text { to resources at any time and in any place) }\end{array}$ & $0.00 \%$ & $21.09 \%$ & $14.06 \%$ & $31.25 \%$ & $33.59 \%$ \\
\hline Ensuring a better business continuity & $7.42 \%$ & $17.19 \%$ & $13.67 \%$ & $37.89 \%$ & $23.83 \%$ \\
\hline $\begin{array}{l}\text { Transferring the responsibility for IT } \\
\text { resource functioning and development to } \\
\text { the provider }\end{array}$ & $0.00 \%$ & $15.23 \%$ & $25.39 \%$ & $36.72 \%$ & $22.66 \%$ \\
\hline $\begin{array}{l}\text { More efficient IT infrastructure } \\
\text { management }\end{array}$ & $0.00 \%$ & $14.84 \%$ & $26.95 \%$ & $26.95 \%$ & $31.25 \%$ \\
\hline Improver cooperation between employees & $0.00 \%$ & $17.19 \%$ & $26.17 \%$ & $28.91 \%$ & $27.73 \%$ \\
\hline $\begin{array}{l}\text { Possibility of unifying and simplifying } \\
\text { organizational procedures }\end{array}$ & $12.89 \%$ & $7.42 \%$ & $24.61 \%$ & $30.86 \%$ & $24.22 \%$ \\
\hline Improvement of IT staff's efficiency & $0.00 \%$ & $23.83 \%$ & $30.47 \%$ & $33.59 \%$ & $12.11 \%$ \\
\hline $\begin{array}{l}\text { Better cooperation with clients and } \\
\text { partners }\end{array}$ & $0.00 \%$ & $23.44 \%$ & $31.64 \%$ & $32.03 \%$ & $12.89 \%$ \\
\hline Lowered need for IT employees & $0.00 \%$ & $18.36 \%$ & $38.67 \%$ & $26.17 \%$ & $16.80 \%$ \\
\hline $\begin{array}{l}\text { Increase of the pace of company's } \\
\text { development (implementation of new } \\
\text { business models) }\end{array}$ & $7.03 \%$ & $18.75 \%$ & $36.72 \%$ & $22.27 \%$ & $15.23 \%$ \\
\hline
\end{tabular}

According to the respondents, the key economic benefit (Table 4) was the reduction of IT-related investment risk ( $63 \%$ of "remarkable benefit” and „great benefit” responses). Furthermore, the surveyed individuals assessed the possibility of minimizing risk and transferring it to an entity specializing in the realization of tasks connected with the management and development of IT solutions to be of importance. 
Table 4

Benefits connected with the implementation of the Cloud-based ERP system in the economic aspect

\begin{tabular}{|llllll|}
\hline Type of benefit & $\begin{array}{l}\text { No } \\
\text { benefit }\end{array}$ & $\begin{array}{l}\text { Slight } \\
\text { benefit }\end{array}$ & $\begin{array}{l}\text { Hard to } \\
\text { tell }\end{array}$ & $\begin{array}{l}\text { Remarkable } \\
\text { benefit }\end{array}$ & $\begin{array}{l}\text { Great } \\
\text { benefit }\end{array}$ \\
\hline Reduction of IT-related investment risk & $3.52 \%$ & $16.02 \%$ & $17.97 \%$ & $35.55 \%$ & $26.95 \%$ \\
\hline $\begin{array}{l}\text { Greater economic efficiency (lowered } \\
\text { investment amount) }\end{array}$ & $5.86 \%$ & $6.25 \%$ & $28.52 \%$ & $30.86 \%$ & $28.52 \%$ \\
$\begin{array}{l}\text { Decrease in costs connected with, inter alia, } \\
\text { management and development of the IT } \\
\text { infrastructure }\end{array}$ & $0.00 \%$ & $17.97 \%$ & $28.91 \%$ & $29.69 \%$ & $23.44 \%$ \\
$\begin{array}{l}\text { Higher IT-related cost predictability and } \\
\text { stability }\end{array}$ & $5.08 \%$ & $19.92 \%$ & $30.86 \%$ & $39.45 \%$ & $4.69 \%$ \\
\hline
\end{tabular}

Other benefits indicated by the respondents ( $59 \%$ of all answers) were: greater economic efficiency understood as lowered investment amount and decrease in costs connected with, inter alia, management and development of the IT infrastructure (53\%). The lowest number of respondents considered higher ITrelated cost predictability and stability to be vital economic benefits - only $44 \%$ of them considered said factors to be of key importance.

Table 5

Benefits connected with the implementation of the Cloud-based ERP system in the societal aspect

\begin{tabular}{|llllll|}
\hline Type of benefit & $\begin{array}{l}\text { No } \\
\text { benefit }\end{array}$ & $\begin{array}{l}\text { Slight } \\
\text { benefit }\end{array}$ & $\begin{array}{l}\text { Hard to } \\
\text { tell }\end{array}$ & $\begin{array}{l}\text { Remarkable } \\
\text { benefit }\end{array}$ & $\begin{array}{l}\text { Great } \\
\text { benefit }\end{array}$ \\
\hline $\begin{array}{l}\text { Development of knowledge and the } \\
\text { stimulation of activity of employees with } \\
\text { regard to more comprehensive IT } \\
\text { technology utilization }\end{array}$ & $7.03 \%$ & $13.67 \%$ & $16.41 \%$ & $34.77 \%$ & $28.13 \%$ \\
\hline $\begin{array}{l}\text { Limiting the need for business trips thanks } \\
\text { to ensuring the possibility of performing } \\
\text { professional tasks in a mobile manner }\end{array}$ & $8.20 \%$ & $16.80 \%$ & $19.92 \%$ & $42.58 \%$ & $12.50 \%$ \\
\hline $\begin{array}{l}\text { Environment protection resulting from the } \\
\text { lower emission of hazardous substances }\end{array}$ & $14.45 \%$ & $18.75 \%$ & $20.70 \%$ & $25.00 \%$ & $21.09 \%$ \\
\hline $\begin{array}{l}\text { Environment protection resulting from the } \\
\text { lower energy consumption }\end{array}$ & $13.28 \%$ & $19.14 \%$ & $34.38 \%$ & $13.28 \%$ & $19.92 \%$ \\
\hline
\end{tabular}

When it comes to the societal aspect (Table 5), the most important benefit of utilizing Cloud-based ERP systems turned out to be the development of knowledge and the stimulation of activity of employees with regard to more comprehensive IT technology utilization ( $63 \%$ of all answers). Aside from that, the surveyed individuals also pointed out to limiting the need for business trips (55\%) and environment protection resulting from the lower emission of hazardous substances (46\%). The respondents attached the least significance to environment protection resulting from the lower energy consumption (33\%). A conclusion can therefore be drawn that among company employees, there was still a limited awareness 
of the impact of the Cloud on the environment at the moment of the survey execution or that the respondents considered the impact of the solution in question on the environment to be vague and difficult to grasp.

Within the framework of the questionnaire, the respondents were also asked about the possible future and impact of Cloud-based solutions on IT-specific technologies within the next 5 years (Fig. 4). The majority of the respondents pointed to the following trends: IT-oriented standardization (82\%), reduction of costs and improvement of quality of IT technologies (71\%), as well as lowered demand for IT experts $(65 \%)$.

The surveyed individuals also predicted that the majority of available IT systems would be offered in the Cloud in the future (63\%) and that Cloud-based solutions would be widely utilized in companies $(57 \%)$.

Only $5 \%$ of all respondents claimed that there would not be any developments with regard to Cloud Computing within the next 5 years. As little as $4 \%$ of the examined people claimed that there would be a severe decline in the popularity of Cloud use in various companies.

\section{Conclusions}

The need for and the willingness to implement modern IT solutions is caused by, among others, remarkable importance of data when it comes to achieving and then maintaining competitive edge. ERP systems are of a remarkable importance in such a context. For quite some time, companies have been able to take advantage of various pieces of software available in the Cloud. Said model is oriented towards using applications and infrastructure made available by external service providers, which makes it easier to focus on basic processes performed by a given firm that result in generating revenue and added value for the client. The user does not need to be knowledgeable with regard to technological solutions (IT infrastructure and software management), because such aspects are being supervised and managed by the service provider.

Current Cloud-based IT solutions are being more frequently utilized by both large-scale and smaller enterprises. It is the result of a number of benefits ensured by Cloud Computing and a constant limitation of drawbacks connected with such a form of acquisition, exploitation, and development of IT and communication-oriented technologies. An important effect of implementing a Cloud-based ERP system that cannot be overlooked is the possibility of making the performed tasks more efficient, optimizing certain processes, and realizing various business strategies. Within the scope of the examination carried out, the authors have attempted to specify the goals of opting for Cloud Computing and identify results of such implementation in Polish enterprises, together with the determination of its impact on the functioning of said firms. Furthermore, the authors have attempted to specify how the respondents assessed both the current and future importance of Cloud-based services. The carried out surveys were preliminary in character. What is more, sample size made it impossible to formulate unequivocal conclusions. Nevertheless, the obtained results have made it possible to positively evaluate the potential and effects of the utilization of Cloud-based solutions in Polish enterprises. As it turns out, the 
respondents were aware of the notable importance of the Cloud that might improve the overall operation of companies. It has to be pointed out that not all of them were aware that Cloud-based solutions might become a foundation for numerous digital transformation-oriented projects. A notable majority of the surveyed individuals recommended Cloud-based ERP systems. No respondent claimed that he or she had not been satisfied with such solutions. The examined people were aware of the importance of Cloud Computing on the IT market and forecasted its further development. After gathering all the acquired pieces of information, it is possible to specify the future direction that will probably be taken by companies interested in the implementation of Cloud-based ERP solutions.

It has to be stated at this point that the outcome of the examinations may present the specificity of the entire branch to a limited extent due to a relatively small sample. Furthermore, the carried out examination does not exhaust a subject and will be elaborated on in the future together with the performance of a more detailed analysis. In the course of future comprehensive examinations, it is vital to analyze whether or not the threats connected with the use of the Cloud may cause delays with regard to strategic adaptations of such IT solutions in Polish enterprises.

\section{Declarations}

\section{Availability of data and materials}

All data generated or analysed during this study are included in this published article.

\section{Competing interests}

The authors declare that they have no competing interests.

\section{Funding}

The authors received no specific funding for this work.

\section{Authors' contributions}

Remigiusz Zieliński and Sebastian Kot conceived of the presented idea. Remigiusz Zieliński developed the theory and performed the computations. Sebastian Kot verified the analytical methods. Remigiusz Zieliński encouraged Katarzyna Zielińska to investigate and supervised the findings of this work. All authors discussed the results and contributed to the final manuscript.

\section{Acknowledgements}

\section{References}

[1] Angadi A., B., Angadi A., B., Gull C., K., Security Issues with Possible Solutions in Cloud 
Computing-A Survey, International Journal of Advanced Research in Computer Engineering \& Technology (IJARCET), 2013, Vol. 2, Iss. 2.

[2] Panetto H., Zdravkovic M., Jardim-Goncalves R., Romero D., Cecil J., Mezgárh I., New perspectives for the future interoperable enterprise systems, Computers in Industry, 2016, Vol. 79, 47-63

[3] Leavitt N., Is Cloud Computing Really Ready for Prime Time?, Computer, Vol. 42., 2009, 15-20

[4] Zhang Q., Cheng L., Boutaba R., Cloud computing: state-of-the-art and research challenges, Journal of Internet Services and Applications, 2010, Vol. 1, Iss. 1, 7-18

[5] Guinard D., Trifa V., Mattern F., Wilde E., From the Internet of Things to the Web of Things: Resourceoriented Architecture and Best Practices, Architecting the Internet of Things, 2001, 97-129

[6] Sulistio A., Reich C., Doelitzscher F., Cloud Infrastructure \& Applications - CloudIA, IEEE International Conference on Cloud Computing, 2009, 583-588

[7] Rani D., Ranjan R., K., A Comparative Study of SaaS, PaaS and laaS in Cloud Computing, International Journal of Advanced Research in Computer Science and Software Engineering, 20014, Vol. 4, Iss. 6, 459461

[8] Goyal S., Public vs Private vs Hybrid vs Community - Cloud Computing: A Critical Review, I.J. Computer Network and Information Security, 2014, 3, 20-29

[9] Jain A., Kumar R., A Taxonomy of Cloud Computing, International Journal of Scientific and Research Publications, 2014, VoL. 4, Iss. 7

[10] Martens B., Teuteberg F., Decision-making in cloud computing environments: $A$ cost and risk based approach, Information Systems Frontiers, 2012, VoL. 14, Iss. 4, 871-893

[11] Zissis D., Lekkas D., Addressing cloud computing security issues, Future Generation Computer Systems, 2012, Vol. 28, Iss. 3, 583-592

[12] Bose R., Luo X., R., Liu Y., The Roles of Security and Trust: Comparing Cloud Computing and Banking, Procedia - Social and Behavioral Sciences, 2013, Vol. 73, 30-34

[13] Jaworski P., Raport ERP perspektywy 2019, ERP-view.pl, 2018, http://erpview.pl/images/perspektywy/RAPORT_ERP_PERSPEKTYWY_2019.pdf, 10.12.2019

[14] Chena C., Lian W., Hsu H., A cloud computing platform for ERP applications, Applied Soft Computing, 2015, Vol. 27, 127-136

[15] Torbacki W., SaaS - direction of technology development in ERP/MRP systems, Archives of Materials Science, 2008, Vol. 32, Iss. 1, 57-60 
[16] Sharma R., Keswani B., Study \& analysis of cloud based ERP services, International Journal of Mechatronics, Electrical and Computer Technology, Vol. 3(9), 2013, 375-396

[17] Ruivo P., Rodrigues J., Oliveira T., The ERP Surge of Hybrid Models - An Exploratory Research into Five and Ten Years Forecast,

[18] Schubert P., Adisa F., Cloud Computing for Standard ERP Systems: Reference Framework and Research Agenda, Fachbereich Informatik, 2011 No. 16

[19] Weng F., Hung M., Cloud ERP: Implementation of Enterprise Resource Planning Using Cloud Computing Technology, Journal of Basic and Applied Scientific Research, 2014, Vol. 5, No. 4, 309-313 [20] Noy C., Sampling Knowledge: The Hermeneutics of Snowball Sampling in Qualitative Research, International Journal of Social Research Methodology, 2008, Vol. 11, Iss. 4.

\section{Figures}

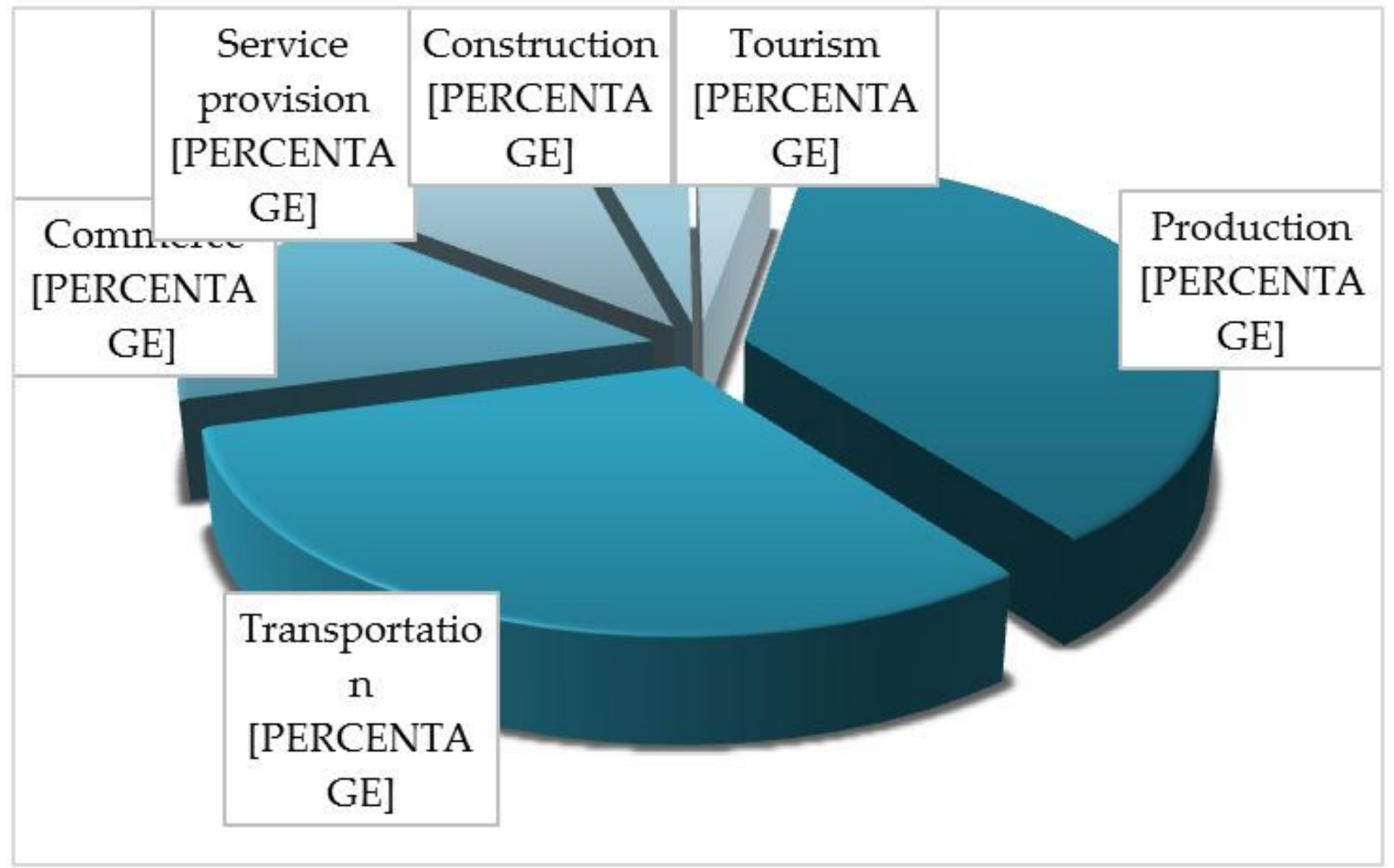

\section{Figure 1}

Research sample with regard to the specificity of business undertakings performed 




Figure 2

Sample structure based on the position held

\section{Cost reduction \\ Easier access \\ Better availability}

Customer servicing quality improvement

Efficiency improvement

Security improvement

Better cooperation with partners

Increased flexibility and scalability

Focus on the basic field of operation

Acquisition of new markets and clients



$\begin{array}{lllllllllll}0 \% & 10 \% & 20 \% & 30 \% & 40 \% & 50 \% & 60 \% & 70 \% & 80 \% & 90 \% & 100 \%\end{array}$ 
Figure 3

Major reasons of implementing Cloud Computing-specific solutions in the company

IT-oriented standardization

Reduction of costs and improvement of..

Decreased demand for IT experts

Entirety of IT system s available in the Cloud

Commonplace utilization of Cloud solution

$$
\text { Variety of uses of CC }
$$

Increase in demand for IT experts

Others

No change

Decrease in the popularity of CC

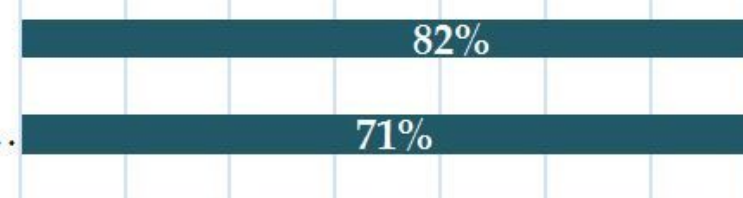

$65 \%$

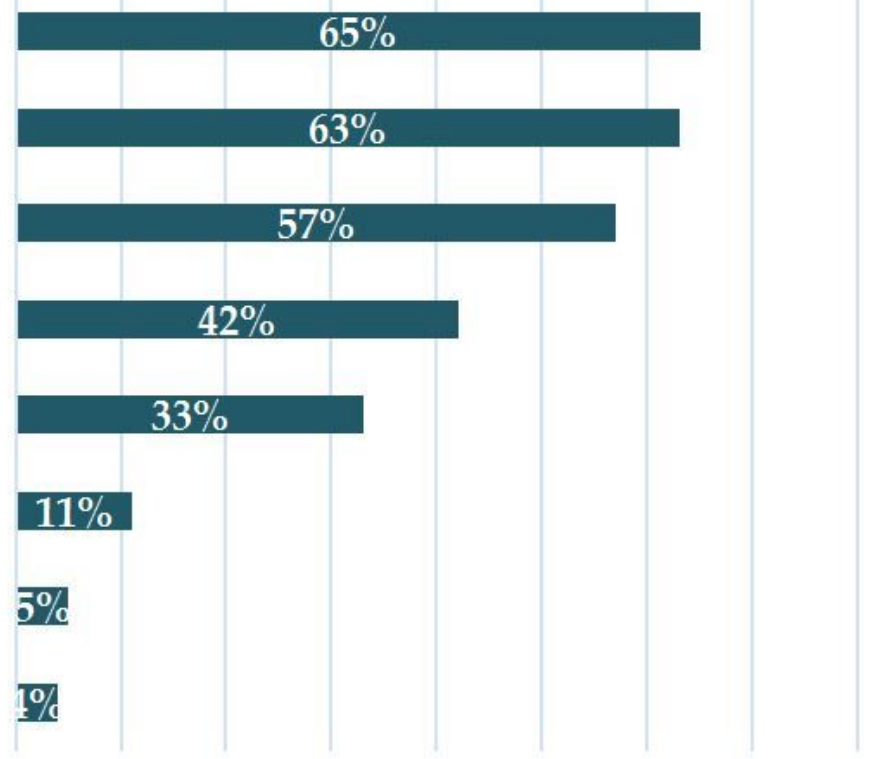

$\begin{array}{llllllllll}0 \% & 10 \% & 20 \% & 30 \% & 40 \% & 50 \% & 60 \% & 70 \% & 80 \% & 90 \%\end{array}$

\section{Figure 4}

Major causes of implementing Cloud solutions in the company 